\title{
Investigation of the frequency and distribution of Pychiatric comorbidities in patients with Mastalgia
}

\author{
Süleyman Dönmezdil', Eşref Araç², Ilhan Taş ${ }^{3}$ Murat Yalçın ${ }^{4}$, Abidin Tüzün ${ }^{5}$ \\ ${ }^{1}$ Assistant Professor, ${ }^{4}$ Medical Doctor, Department of Psychiatry, ${ }^{2}$ Assistant Professor, Department of Internal Medicine, \\ ${ }^{3}$ Medical Doctor, ${ }^{5}$ Assistant Professor, Department of General Surgery, University of Health Sciences, Diyarbakır Gazi \\ Yasargil Training and Research Hospital, Diyarbakır, Turkey
}

Background: Mastalgia defines pain that is located in or felt in the breast area. Pain can be a symptom in many psychiatric disorders. Therefore, considering the psychiatric disorders in the evaluation of patients with mastalgia is of great importance in terms of treatment success and pain control. Aims and Objective: In this study, we aimed to identify the psychiatric diagnoses that may be involved in the etiology of mastalgia and to retrospectively determine the frequency of patients who may need psychiatric treatment among the treatment options that can be used in patients with mastalgia. Materials and Methods: We included patients who presented with breast pain between August 2017 and August 2018 and had normal results of radiological imaging studies. The archive system of the hospital was screened for the presence of any psychiatric admission before the diagnosis and previous psychiatric diagnoses, if any, were recorded. Results: There were 1124 patients with mastalgia included in our study. Screening of psychiatric comorbidities recorded in the archive system revealed the presence of psychiatric admissions in $19.04 \%$ ( $n=214$ ) of the patients. Student's t-independent test showed a statistically significant difference between the mean age of mastalgia patients with and without psychiatric comorbidity. Conclusion: In our study, we demonstrated the presence of anxiety disorder as psychiatric comorbidity in a high percentage of patients $(43.9 \%)$, which was consistent with the rates reported in the literature of somatic symptoms, which are associated with anxiety disorder.

Key words: Breast pain; Mastalgia; Psychiatric disorders; Somatization

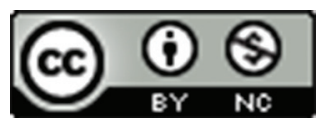

This work is licensed under a Creative Commons Attribution-NonCommercial 4.0 International License.

\section{INTRODUCTION}

Mastalgia defines pain that is located in or felt in the breast area. ${ }^{1}$ More specifically, it is the most common benign breast disorder that can be defined as breast tenderness that occurs before the luteal phase of the menstrual cycle in women of childbearing age., ${ }^{2,3}$

Pain can be a symptom in many psychiatric disorders. Therefore, considering the psychiatric disorders in the evaluation of patients with mastalgia is of great importance in terms of treatment success and pain control. ${ }^{4}$
Mastalgia is a disorder that deteriorates the quality of life, causes loss of labor and leads to a significant increase in treatment costs. Studies in the literature have reported that patients with severe mastalgia experience significant problems with sexual life $(48 \%)$, followed by physical (36\%), social (13\%), and work/school problems $(6 \%) .5,6$

It has been noted that pain is a significant complaint in 50 to $60 \%$ of depressed patients, and $60 \%$ of patients with pain have depressive symptoms. In addition, pain-related complaints are defined in patients diagnosed with anxiety and somatization disorders. ${ }^{7}$ 
In addition to pharmacological agents, psychiatric therapeutic modalities have been successful in the treatment of breast pain. A study showed that patients with mastalgia had a significant reduction in pain scores compared to the control group by relaxation therapy with tapes and provided evidence of a significant improvement in $61 \%$ of patients. ${ }^{7}$ Another study showed that suggestion therapy was beneficial, with a decrease in the frequency of outpatient admissions by patients with a reduction or termination of pain complaints and a regression of complaints after suggestion treatment in $85 \%$ of patients. $^{8}$

In this study, we aimed to identify the psychiatric diagnoses that may be involved in the etiology of mastalgia and to retrospectively determine the frequency of patients who may need psychiatric treatment among the treatment options that can be used in patients with mastalgia.

\section{MATERIALS AND METHODS}

We included patients who presented with breast pain between August 2017 and August 2018 and had normal results of radiological imaging studies. The archive system of the hospital was screened for the presence of any psychiatric admission before the diagnosis and previous psychiatric diagnoses, if any, were recorded. During the preparation of the data, the presence and type of psychiatric diagnoses were recorded. Patients with benign or malignant findings on any imaging modality were excluded from the study.

Ethical approval for our study was obtained from institutional ethical committee of Gazi Yaşargil Training and Research Hospital (Protocol number: 121; approval date $06 / 08 / 2018$ ). The main objective of this study was to determine the psychiatric comorbidities and etiological causes of patients diagnosed with mastalgia and to contribute to the increase of the treatment options available to health professionals.

\section{Statistical analysis}

In our study, numerical data were expressed as mean \pm standard deviation, whereas categorical data were expressed as frequency (percentage). Statistical analysis was performed using Statistical Package for Social Sciences (SPSS) software version 10.0 (SPSS, Chicago, Ill., USA). The normality distribution of numerical data was determined by using Shapiro-Wilks test, while homogeneity of numerical data was tested using Levene's test. Chi-square and Student's-t independent tests were used for statistical analysis. A P value less than. 05 was considered to be the limit of statistical significance.

\section{RESULTS}

There were 1124 patients with mastalgia included in our study. Screening of psychiatric comorbidities recorded in the archive system revealed the presence of psychiatric admissions in 19.04\% $(n=214)$ of the patients.

The diagnoses established in psychiatric admissions were categorized as anxiety disorder, depression, mixed anxiety and depressive disorder, somatoform disorders and others (adjustment disorder, psychosis, mood disorders etc.).

The mean age of all patients diagnosed with mastalgia was $38.59 \pm 12.97$ years $(n=1124)$. The mean age of mastalgia patients with and without psychiatric comorbidity was $40.5 \pm 12.74$ years $(n=214)$ and $38.14 \pm 12.98$ years ( $n=910)$, respectively. Student's t-independent test showed a statistically significant difference between the mean age of mastalgia patients with and without psychiatric comorbidity $(\mathrm{p}<0.01)$ (Table 1).

The categorization of all mastalgia patients by age showed a rate of $57.3 \%(\mathrm{n}=644)$ for those aged 40 years and below, and $42.7 \%(\mathrm{n}=480)$ for those older than 40 years.

There was no statistically significant difference in the presence of psychiatric comorbidities between the age groups (40 years and under and over 40 years) (Table 2).

Of the 1124 patients with mastalgia, $57.3 \%(n=644)$ were 40 years old and younger, while $42.7 \%(n=480)$ were older than forty years. The rate of patients with psychiatric comorbidity among all groups was $19 \%(\mathrm{n}=214)$.

The diagnostic distribution in patients with a psychiatric comorbidity was as follows: anxiety disorder in $43.9 \%$ $(\mathrm{n}=94)$, depression in $22 \%(\mathrm{n}=47)$, mixed anxiety and depressive disorder in 15.4\% $(\mathrm{n}=33)$, somatoform disorders in $8.4 \%(\mathrm{n}=18)$ and other in $10.3 \%(\mathrm{n}=22)$ (Table 2).

Table 1: The relationship between the ages of
mastalgia patients with and without psychiatric
comorbidity




\begin{tabular}{|c|c|c|c|c|c|c|c|c|}
\hline & \multicolumn{6}{|c|}{ Psychiatric comorbidities } & \multirow[t]{2}{*}{ Total } & \multirow[t]{2}{*}{$\mathbf{p}$} \\
\hline & No. & $\begin{array}{l}\text { Anxiety } \\
\text { disorder }\end{array}$ & Depression & $\begin{array}{l}\text { Mixed anxiety and } \\
\text { depressive disorder }\end{array}$ & $\begin{array}{l}\text { Somatoform } \\
\text { disorders }\end{array}$ & Other & & \\
\hline 40 years and under & 535 & 45 & 27 & 16 & 7 & 14 & 644 & 8.145 \\
\hline Over 40 years & 375 & 49 & 20 & 17 & 11 & 8 & 480 & 0.148 \\
\hline Total & 910 & 94 & 47 & 33 & 18 & 22 & 1124 & \\
\hline
\end{tabular}

\section{DISCUSSION}

For the treatment of somatic symptoms in psychiatric disorders, there are frequent references to non-psychiatric departments. Studies have reported that patients may refer to non-psychiatric departments for all psychiatric diagnoses, with a higher frequency for anxiety and somatization disorders. ${ }^{\text {? }}$

Diagnosis of mastalgia can be established by interdisciplinary consultation between general surgeon and radiologist. It should be kept in mind that, although mastalgia has a psychogenic origin and therefore needs psychiatric therapy, there will be no regression in complaints due to non-initiation of treatment, which may lead to repeated outpatient visits. ${ }^{10}$ This can sometimes lead to the use of multiple imaging modalities and loss of labor with increased health expenditure.

The lack of complete elucidation of the etiology of mastalgia causes limitation of treatment options. Researchers have conducted research on the etiology of mastalgia, considering that it may include a psychiatric disorder.

In a study of 40 patients with mastalgia and 40 healthy volunteers, Kanat et al. found an increase in the scores of anxiety and depression scales in the mastalgia group. In addition, a significant decrease was found in the scores of the quality of life scale in the mastalgia group. This study indicates that there is a severe decline in quality of life in women suffering from breast pain, which in turn may lead to loss of labor. ${ }^{11}$

In another study on 1219 females, Johnson et al. found breast pain-related complaints and mastalgia in $85 \%$ and $15 \%$ of the participants, respectively. In this study, which included participants with a mean age of 47 years, they reported statistically significantly higher rates of the history of post-traumatic stress disorder, panic disorders, major depression, eating disorders and domestic violence in the mastalgia group compared to other groups. ${ }^{12}$

In a study of 70 patients and 70 healthy volunteers with a mean age of 32 years, Yllmaz et al. applied the Generalized Anxiety Disorder-7 (GAD-7) scale and the visual analogue scale (VAS) in patients and healthy volunteers who did not have any organic etiology, which was ruled out by radiological imaging methods, and showed that the scores of the scales were significantly higher in the mastalgia group compared to the control group. ${ }^{13}$

In our study, the mean age of the group with a psychiatric comorbidity was $40.5 \pm 12.74$ years. The basic information is that the mean age of onset of mastalgia is 40 years, which is consistent with the data of our study.

Our study reported the presence of psychiatric comorbidity in a high percentage of patients $(19 \%)$, which led us to investigate any psychiatric etiology of mastalgia in accordance with the literature. ${ }^{14}$

It should be noted that mastalgia may have a psychiatric etiology or may be associated with a psychiatric disorder, as reported in similar studies mentioned above. The need for psychiatric treatment should not be overlooked in breast pain where an organic etiology has been ruled out by means of a detailed anamnesis.

\section{LIMITATIONS}

Limitations of our study include the lack of classification of mastalgia due to a retrospective study design and the possibility of having a psychiatric diagnosis in another center. Because we were able to obtain the diagnoses established only in the admissions to our center.

\section{CONCLUSION}

In our study, we demonstrated the presence of anxiety disorder as psychiatric comorbidity in a high percentage of patients (43.9\%), which was consistent with the rates reported in the literature of somatic symptoms, which are associated with anxiety disorder.

Our study differs from other studies in that it reports the frequency of mastalgia in common psychiatric diagnoses. Because, other studies have investigated the frequency of mastalgia by means of scales for a few limited diagnoses. 
Large-scale prospective randomized studies are needed to elucidate the etiology of mastalgia and to discover the applications that will contribute to the complete elimination of pain and other symptoms with an effective treatment modality.

\section{REFERENCES}

1. Rathi J, Chawla I, Singh K and Chawla A. Centchroman as Firstline Treatment for Mastalgia: Results of an Open-label, Singlearm Trial. Breast J 2016; 22(4):407-412.

https://doi.org/10.1111/tbj.12593

2. Genç A, Celebi MM, Çelik SU, Atman ED, Kocaay AF, Zergeroğlu AM, et al. The effects of exercise on mastalgia. Phys Sportsmed 2017;45:17-21.

https://doi.org/10.1080/00913847.2017.1252702

3. Niazi A, Rahimi VB, Hatami H, Shirazinia R, Esmailzadehdizaji $\mathrm{R}$, Askari $\mathrm{N}$, et al. Effective Medicinal Plants in the Treatment of the Cyclic Mastalgia (Breast Pain): A Review. J Pharmacopuncture 2019; 22(3):131-139.

4. Smith RL, Pruthi $S$ and Fitzpatrick LA. Evaluation and management of breast pain. Mayo Clin Proc 2004;79(3):353-372. https://doi.org/10.4065/79.3.353

5. Ader DN and Shriver CD. Cyclical mastlgia: Prevalence and impact in an outpatient breast clinic sample. J Am Coll Surg 1997; 185:466-467.

6. Ader DN, Shriver CD and Browne MW. Relationship of cyclical mastalgia. Premenstrual syndrome or recurrent pain disorder. Am J Obstetric and Gynecology 1997; 20:198-202. https://doi.org/10.3109/01674829909075596

7. Dilbaz N, Özen AR, Ozan G and Güz H. Ağrı yakınması olan hastalarda psikyatri morbidite. IV. Ulusal Konsültasyon-Liyezon Psikiyatrisi Kongresi Bildiri Kitapçığı 1996; 1:226-235.

8. Fox H, Walker LG, Heys SD, Ah-See AK and Eremin O. Are patients with mastalgia anxious and does relaxation therapy help? Breast 1997; 6: 138-142.

9. Çakır T, Cingi A, Fıstıkçı N, Bez Y, Topçuoğlu V and Güllüoğlu BM. Organik bir nedene bağlı olmayan mastalji yakınması olan hastalarda telkinin yeri: prospektif kesitsel çalışma. Meme Sağlığı Dergisi 2006; 2: 96-99.

10. Fink P. The use of hospitalizations by persistent somatizing patients. Psychol Med. 1992; 22(1):173-180. https://doi.org/10.1017/S0033291700032827

11. Colegrave S, Holcombe $\mathrm{C}$ and Salmon P. Psychological characteristics of women presenting with breast pain. J Psychosom Res 2001;50:303-307.

12. Kanat BH, Atmaca M, Girgin M, Ilhan YS, Bozdağ A, Özkan Z, et al. Effects of Mastalgia in Young Women on Quality of Life, Depression, and Anxiety Levels. Indian J Surg 2016r; 78(2):96-99.

https://doi.org/10.1007/s12262-015-1325-5

13. Johnson KM, Bradley KA, Bush K, Gardella C, Dobie DJ and Laya MB. Frequency of mastalgia among women veterans. Association with psychiatric conditions and unexplained pain syndromes. J Gen Intern Med 2006; 21 Suppl 3:S70-S75. https://doi.org/10.1111/j.1525-1497.2006.00378.x

14. Yılmaz EM, Çelik S, Arslan H and Değer D. Relation between Mastalgia and Anxiety in a Region with High Frequency of Posttraumatic Stress Disorder. J Breast Health 2015;11(2):72-75. https://doi.org/10.5152/tjbh.2015.2363

15. Goodman JH, Chenausky KL and Freeman MP. Anxiety disorders during pregnancy: a systematic review. J Clin Psychiatry 2014; 75:e1153-e1184.

https://doi.org/10.4088/JCP.14r09035

\section{Authors Contribution:}

SD- Concept and design of the study, manuscript preparation, statistically analyzed and interpreted, critical revision of the manuscript, review of the study:

EA- Concept and design of the study, manuscript preparation, statistically analyzed and interpreted, critical revision of the manuscript, review of the study;

IT- Reviewed the literature, collected data, statistically analyzed and interpreted, helped in preparing first draft of manuscript, review of the study; MY- Reviewed the literature, collected data, statistically analyzed and interpreted, helped in preparing first draft of manuscript, review of the study; AT- Reviewed the literature, collected data, statistically analyzed and interpreted, helped in preparing first draft of manuscript, review of the study.

\section{Work attributed to:}

University of Health Sciences, Diyarbakır Gazi Yasargil Training and Research Hospital, Elazığ Road, Kayapınar, Diyarbakır, Turkey. -21070

Orcid ID:

Dr. Süleyman Dönmezdil- (D) http://orcid.org/0000-0002-7171-1374

Dr. Essref Araç- (i) http://orcid.org/0000-0001-6041-3817

Dr. İlhan Taş- (iD http://orcid.org/0000-0002-6624-8063

Dr. Murat Yalçın- (1) http://orcid.org/0000-0001-9813-7862

Dr. Abidin Tüzün- (1) http://orcid.org/0000-0002-4953-6602

Source of Support: None, Conflict of Interest: None. 